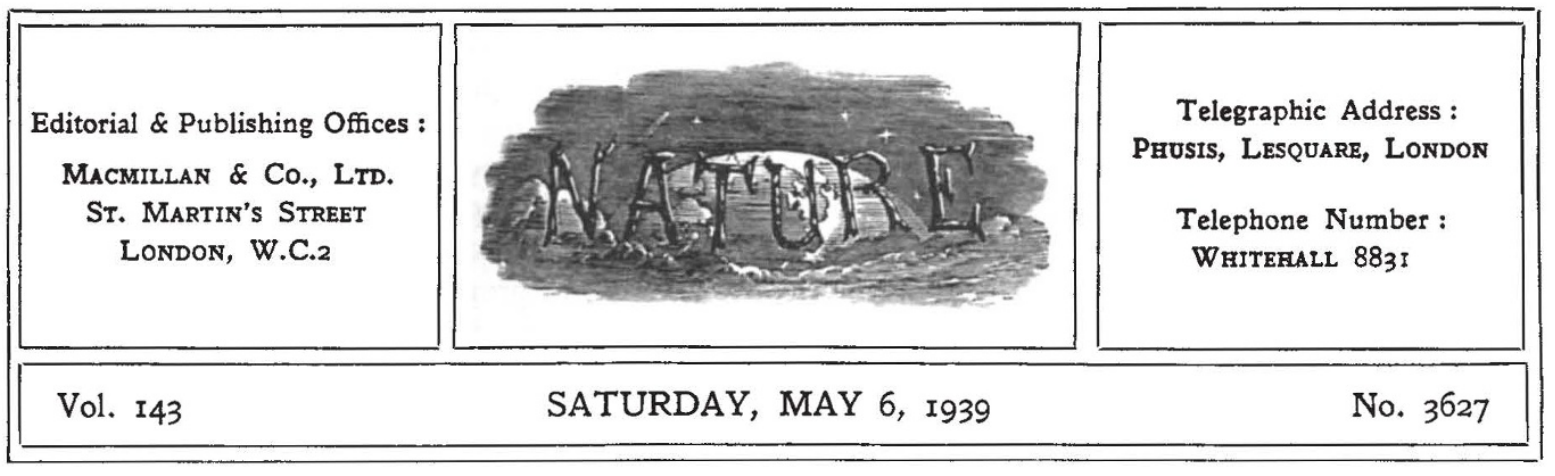

\title{
Industrial Development and Social Welfare
}

$F^{\prime \prime m}$ EW major questions have emerged so rapidly from the theoretical to the practical stage in recent years as that of the location of industry. When the problems of the location of industry in Great Britain were first discussed by Political and Economic Planning (P E P) in 1931, the idea of guiding the location of industry was generally dismissed as impracticable, and little improvement in public opinion was discernible when P E P in 1935 first began the preparation of its report on this question, a summary of which appears elsewhere in this issue (p. 770). Since then, however, many authorities and considerations have stressed the importance and urgency of attention to the complex problems which this question presents.

This was one of the main points mado by Lord Stamp in urging the establishment of a Royal Commission upon population changes and the agencies required to deal with questions arising from these problems as they develop. A programme of research proposed by a group of experts in the universities, quoted by Lord Stamp in his "The Science of Social Adjustment", includes a quantitative investigation of regional distribution of population with reference, among other matters, to the location of industry. The report of the Town Planning Institute last year, recommending a National Advisory Board, directed attention to the importance of recognizing trends in population changes due to the location of industry as well as to changes in age distribution and the declining birth-rate.

Already in 1934, in endowing the Commissioners for the Special Areas with financial and other powers to induce industries to locate themselves in areas of unemployment, Parliament has given a limited shape to the public concern that industrial enterprise should be so prompted and directed that it would meet effectually the requirements of the community, not only in the supply of goods and services at the point where they are wanted, but also in the supply of employment where it is wanted. The reality of that public concern finds further expression in the view asserted in Parliament and elsewhere that the Special Areas Act itself is an experiment to determine the value to these areas of providing special treatment, and to learn whether the results obtained warrant a wider application. The pressure of opinion which compelled the Government early in 1937 to over-rule a departmental decision to build an aircraft factory in the Maidenhead district sprang as much from growing awareness of the necessity of long-range statesmanship and resolute scientific investigation in the interlocked problems of town planning, location of industry, national health and defence and the provision of amenities, as from the threat to amenities and the vulnerability of a factory contiguous with the Greater London area.

The dangers of the excessive concentration in the Greater London area were emphasized in many ways at the time of the September crisis last year, and planned control of the growth of London has been advocated by Sir Raymond Unwin before the Garden Cities and Town Planning Associations. Since then, the question of planning the location of industry in regard to defence has assumed increasing importance as a factor in defence against air attack, and defence considerations have to be taken into account in any system of State guidance or location of industry.

The $\mathrm{P}$ E $\mathrm{P}$ report leaves no room for doubt as to the complexity of the problem and its dynamic rather than static character. Essentially the location of industry involves the problem of the 
use of the land. This is the affair of town and country planning and of land management. With this particular aspect, local authority planning committees, the Ministry of Health, individual landowners and agents in charge of public or semi-public estates are already dealing. The chief need here is to secure a better informed and more co-ordinated type of development, through a central planning body able to collect the necessary information and use it in guiding the local authorities concerned. Some pooling of ownership and management, in the public interest, of land in and around growing towns may also be required.

Secondly, there is involved the maintenance of a balance between different regions of Great Britain which will prevent some from exploiting and sapping the vitality of others, and in particular prevent London from dominating further and enfeebling the life of the rest of the country. The third problem is regional development and the guidance of the location of industry. This problem affects the industrialist, the utility services, the Board of Trade and the Ministries of Labour and Transport, just as the second concerns public administration, aided by the universities, the British Broadcasting Corporation and other cultural agencies.

The report frankly recognizes that a long-term policy is involved, and that many years may pass before the full effect of that policy is felt, even if a number of immediate steps could be taken to improve the present situation or minimize its dangers. The first need is, however, the elaboration of a definite and constructive national policy, and in this a clear statement of objectives is required. The State, it is true, cannot be expected to avert the consequences to industries of natural phenomena, technical progress or international forces. At the best it can only mitigate them. When, however, the odds are lengthening against the selection, by the most far-sighted industrialist, of a location which will remain economic for him for a long period, owing to the increasing rate of technological change and the multiplication of extraneous and unpredictable factors, it is essential that the State be prepared to establish services which will enable the industrialist to perform his function more efficiently.

To promote the efficient functioning of industry without detriment to existing standards of living or disruption of society is one of the first objects of national industrial policy. A second objective must be the co-ordination of the many State activities which affect industry and economics, so as to eliminate overlapping and waste and to co-ordinate the provision of State services generally with industrial requirements over a long period. Powers will also be required to curb the activities of the minority of economic pirates whose influence may be out of proportion to their numbers, and it is now necessary for the State to possess powers to direct the nature of industrial development with reference to the requirements of national security.

The primary need, accordingly, is a well-formulated but flexible policy which will guide the use of all national resources. In several spheres a start has already been made in this direction : the unification of coal royalties in the hands of the Coal Commission, the establishment of the Electricity Commission and of the Central Electricity Board, as well as the unification of numerous local bodies into catchment boards, being examples. As yet, however, the control of the use of the land under the Town and Country Planning Act, which must form the starting-point of any form of actual control over national resources, is scarcely effective, and it is evident that local authorities should be given more explicit guidance in the principles they should observe.

Industrial location is, of course, a wider problem, involving a balance between the varied economic requirements of the community and the requirements of the manufacturer, and a fundamental conclusion of the report is that it requires treatment as a whole on a national as well as on a regional or local scale. Reconditioning of the present Special Areas and the prevention of the recurrence of the same troubles elsewhere can only be a gradual process. Permanent machinery is required for guiding and adjusting industrial growth.

Extension of national action in this respect would. require a reassessment of priorities, and this in turn involves the collection of information and the evolution of a satisfactory method of measurement. Existing methods of measurement have scarcely been adequate for the complex problems of measuring the current prosperity and future prospects of localities, and accordingly one of the major tasks of the Industrial Development Commission proposed in the report would be the provision of a centralized information service to assist industrialists in the choice of sites and locations of new plant and in problems of industrial development generally.

This proposed Commission would accordingly be charged with the responsibility of keeping under 
review factors affecting the efficient operation of industry, with particular reference to those factors arising from the choice of location. It should be empowered to publish information concerning the facilities available for the establishment of factories in all suitable areas. It should be provided that the services of the officers of the Commission would be available for prior consultation by persons desiring to apply for licences in respect of new factories or extensions.

This is regarded as one of the most important sections of the work of the proposed Commission, and the smooth working of the machinery as a whole would probably depend largely upon the success achieved by the Commission in collecting and disseminating information and advice calculated to assist manufacturers in this matter. An efficient central advisory service, in practice, might obviate all question of compulsion in the majority of individual cases, since the choice of a suitable site would be determined in amicable agreement, and confirmation of that choice through the licensing machinery would then be a formality. Moreover, such a service, on the basis of continued research, should relieve industrialists of the laborious and wasteful task of conducting their own preliminary investigations, and present the relevant facts for consideration much more rapidly and lucidly. It might also put before the industrialist factors he might otherwise overlook, such as the interest of the industrialist as well as of the community in creating and maintaining a reasonable balance of industries within broad economic regions.

The organization of an efficient information service is largely a matter of intensive economic research into the growth of industry and the factors affecting it, and of ensuring that the service is recognized by industry and used in practice as a matter of course. The task of undertaking the necessary research and keeping the information up to date should not, however, be under-estimated. It involves, for example, the determination of the economic regions into which Great Britain would be divided by the Commission, and the needs of those regions in relation to industrial balance. A comprehensive knowledge of sites available and suitable for further industrial development is essential as well as a full knowledge of the existing distribution of industry and of national resources generally. It also involves the determination of a line of policy with regard to social and strategic considerations in relation to the distribution of unemployment, vulnerability to attack and other factors.

We have here, in fact, a scientific approach and a programme of research which have long been advocated by those within the ranks of scientific workers or without, who have sought to approach these complex problems in the spirit of science. This alone should commend the report and its recommendations to the interest and support of scientific workers, while the value and magnitude of this preparatory work are indicated in the opinion expressed in the report that a considerable interval would be justified between the establishment of the Commission and the coming into force of certain of its executive powers, such as the licensing provisions.

The second main purpose of the Industrial Development Commission recommended by the report is the co-ordination of policies and actions of central and local government authorities, public utilities and other institutions, and it is in pursuance of the task of guiding the future location of industry, to avoid the repetition and multiplication of mistakes of the past, that the report suggests that the Commission should be charged with the responsibility of licensing new factories or extensions to existing factories. Such powers of restraint are regarded as essential, although it is believed that only rarely would it be necessary for the Commission to exercise its veto. Not the least service of the report is the way in which, fairly but undisguisedly, it puts the case for such compulsion.

These proposals of the report in regard to the licensing of new factories and evacuation and resettlement schemes for derelict areas, radical as they seem, are only the logical extension of principles which have already been tentatively adopted. Moreover, the clear but far-sighted statement of the principles of evacuation or re-settlement which the report contains should dissipate controversy on general ideas and facilitate the elaboration and execution of detailed plans, even if the financial estimates of the report prove to be somewhat optimistic. The conception of spending to create a model town, instead of prolonging the life of one that is moribund, is essentially in keeping with a scientific policy, and the bold constructive proposals of this report have strong claims on the attention of all scientific workers who are in sympathy with its underlying conception of a new co-operation both in form and in purpose for the integration of industrial expansion and social welfare and stability. 